\title{
Bur open The Sydney Multisite Intervention of LaughterBosses and ElderClowns (SMILE) study: cluster randomised trial of humour therapy in nursing homes
}

\author{
Lee-Fay Low, ${ }^{1}$ Henry Brodaty, ${ }^{1}$ Belinda Goodenough, ${ }^{1}$ Peter Spitzer, ${ }^{2}$ \\ Jean-Paul Bell, ${ }^{3}$ Richard Fleming, ${ }^{4}$ Anne-Nicole Casey, ${ }^{1}$ Zhixin Liu, ${ }^{1}$ \\ Lynn Chenoweth ${ }^{5}$
}

To cite: Low L-F, Brodaty $\mathrm{H}$, Goodenough B, et al. The Sydney Multisite Intervention of LaughterBosses and ElderClowns (SMILE) study: cluster randomised trial of humour therapy in nursing homes. BMJ Open 2013;3: e002072. doi:10.1136/ bmjopen-2012-002072

- Prepublication history for this paper are available online. To view these files please visit the journal online (http://dx.doi.org/10.1136/ bmjopen-2012-002072).

Received 10 September 2012 Revised 15 November 2012 Accepted 10 December 2012

This final article is available for use under the terms of the Creative Commons Attribution Non-Commercial 2.0 Licence; see http://bmjopen.bmj.com

For numbered affiliations see end of article

Correspondence to Dr Lee-Fay Low; If.low@unsw.edu.au

\section{ABSTRACT}

Objectives: To determine whether humour therapy reduces depression (primary outcome), agitation and behavioural disturbances and improves social engagement and quality-of-life in nursing home residents.

Design: The Sydney Multisite Intervention of LaughterBosses and ElderClowns study was a singleblind cluster randomised controlled trial of humour therapy.

Setting: 35 Sydney nursing homes.

Participants: All eligible residents within geographically defined areas within each nursing home were invited to participate.

Intervention: Professional 'ElderClowns' provided 9-12 weekly humour therapy sessions, augmented by resident engagement by trained staff 'LaughterBosses'. Controls received usual care.

Measurements: Depression scores on the Cornell Scale for Depression in Dementia, agitation scores on the Cohen-Mansfield Agitation Inventory, behavioural disturbance scores on the Neuropsychiatric Inventory, social engagement scores on the withdrawal subscale of Multidimensional Observation Scale for Elderly Subjects, and self-rated and proxy-rated quality-of-life scores on a health-related quality-of-life tool for dementia, the DEMQOL. All outcomes were measured at the participant level by researchers blind to group assignment.

Randomisation: Sites were stratified by size and level of care then assigned to group using a random number generator.

Results: Seventeen nursing homes (189 residents) received the intervention and 18 homes (209 residents) received usual care. Groups did not differ significantly over time on the primary outcome of depression, or on behavioural disturbances other than agitation, social engagement and quality of life. The secondary outcome of agitation was significantly reduced in the intervention group compared with controls over 26 weeks (time by group interaction adjusted for covariates: $p=0.011$ ). The mean difference in change from baseline to 26 weeks in Blom-transformed agitation scores after adjustment for covariates was 0.17 ( $95 \% \mathrm{Cl} 0.004$ to $0.34, \mathrm{p}=0.045)$.

Conclusions: Humour therapy did not significantly

\section{ARTICLE SUMMARY}

Article focus

- The Sydney Multisite Intervention of LaughterBosses and ElderClowns (SMILE) study is a cluster randomised controlled trial evaluating the effect of humour therapy on depression, agitation, behavioural disturbances, social engagement and quality-of-life in nursing home residents.

Key messages

- Humour therapy was not shown to impact on depression (main outcome), behavioural disturbances other than agitation, social engagement or quality-of-life.

- Humour therapy was successful in reducing agitation in the intervention at 13-week and 26-week follow-up relative to controls who received usual care.

- Humour therapy should be considered as a psychosocial intervention to reduce agitation, before starting medication.

Strengths and limitations of this study

- SMILE offered a novel model of humour therapy that combined staff training (LaughterBosses) and 12 visits by professional performers (ElderClowns).

- The sample size was large involving 398 residents living in 35 Sydney nursing homes: 17 homes in the intervention group and 18 in the usual care group.

- Data collection staff were unblinded to treatment allocation in 15 of the 35 homes.

- There was variation in the number of ElderClown visits and LaughterBoss initiated humour received by individual residents.

- The study had lower power to detect effects than expected due to higher than expected intracluster correlations.

reduce depression but significantly reduced agitation. Trial registration: Australian New Zealand Clinical Trials Registry -ACTRN12611000462987. 


\section{INTRODUCTION}

Humour is a fundamental form of social play with many psychological benefits: facilitating positive emotions that in turn may increase problem solving and memory efficiency; facilitating social communication, social influence and bonding and tension relief and coping with anxiety. ${ }^{1}$ Humour therapy involves using humour to facilitate laughter and happiness. The humour can be delivered by an individual (eg, by a clown) or recorded stimuli (eg, a video) or participants can be shown how to generate humour themselves. Anecdotally, humour interventions result in positive outcomes; however, the research evidence is limited. Small experimental studies with randomised or quasi-randomised designs have reported beneficial effects of humour interventions on a diverse range of outcomes, such as: pregnancy rates during in vitro fertilisation, ${ }^{2}$ reducing preoperative anxiety in children, ${ }^{3}$ lowering diastolic blood pressure, respiratory frequency and temperature in children with respiratory pathologies, ${ }^{4}$ and in decreasing depression and insomnia in older persons. ${ }^{5}{ }^{6}$ While people living with dementia appreciate and can express themselves with humour, ${ }^{7}{ }^{8}$ there are seldom opportunities to experience humour when living in a nursing home. ${ }^{9}$

Five of the six studies evaluating the efficacy of humour therapy in nursing home residents reported some benefit, ${ }^{10-15}$ albeit limited by small sample sizes, relatively low-quality methodology and lack of flexibility in matching humour techniques to residents' abilities and preferences. ${ }^{10} 15$ A non-controlled study $(n=21)$ of four clown sessions, evaluated using a modified dementia care mapping protocol, found an overall increase in positive behaviours and decrease in negative behaviours during the sessions in persons with severe dementia; however, there was no follow-up outside the sessions. ${ }^{10} \mathrm{~A}$ non-randomised controlled study $(n=61)$ found that five sessions of comical singing and dancing were associated with decreased self-rated anxiety and depression in nursing home residents. ${ }^{11}$ Fortnightly group humour therapy for psychiatric in-patients with either Alzheimer's disease, or late-life depression, did not improve quality-of-life for either group in addition to standard pharmacotherapy $(n=20) .{ }^{15}$ Nursing home residents $(n=87)$ randomly assigned to watch humorous movies three times a week showed decreased negative affect following the 12-week intervention compared with both those residents who watched serious movies and controls who received usual care. ${ }^{12}$ Residents (n=27) randomly assigned to watch recordings of humorous story-telling weekly for 12 weeks reported improved quality-of-life compared to those who watched conventional television and those who received usual care. ${ }^{13}$ Eight weekly sessions involving telling jokes, and funny stories and discussions on prioritising humour in daily life decreased reports of pain and perceived loneliness, and increased reported happiness and life satisfaction in residents in the intervention group $(n=36)$ compared with controls $(n=34) .{ }^{14}$
The primary aim of the Sydney Multisite Intervention of LaughterBosses and ElderClowns (SMILE) (Australian New Zealand Clinical Trials Registry number ACTRN12611000462987) was to evaluate the effectiveness of humour therapy in improving mood in individual residents living in nursing homes. Secondary aims were to investigate the effectiveness of humour therapy on decreasing agitation and other behavioural disturbances, and increasing quality-of-life and social engagement of residents. We utilised a clustered design with randomisation at the facility level as the intervention involved training staff to change their behaviour towards residents, which is difficult to contain to only certain residents within their care.

\section{METHODS}

A single-blind two-group longitudinal cluster randomised controlled design was used in SMILE to evaluate humour therapy in Australian nursing homes. The Study protocol details have been reported previously. ${ }^{16}$ Ethics approval was obtained from the University of New South Wales Human Research Ethics Committee (approval number 08345). Residents either provided written consent, if judged by the researcher as being able to understand information about the study and make an informed decision about participation, or verbal assent, if incapable of providing written consent, with written consent obtained from a proxy.

\section{Participants}

Invitations were made to 228 nursing homes located in Sydney, Australia. Eligible homes were: government accredited; located within greater metropolitan Sydney within $1 \mathrm{~h}$ drive from the University of New South Wales, Sydney; not enrolled in another intervention study; not catering for particular ethnic and minority groups or medical conditions except for dementia; not scheduled for change in management, renovation or programme delivery; able to secure site-specific governance permission and in agreement with study terms. After screening, the first 36 eligible homes were randomised to an intervention or a control group. Eight additional eligible homes on a waiting list replaced homes that withdrew before baseline. One home that began the intervention and was subsequently found to be ineligible because it catered specifically to persons with mental illnesses and drug and alcohol addiction was immediately excluded. Data collection occurred in six rolling cycles between July 2009 and May 2011.

Within each home, a geographical SMILE neighbourhood was defined following discussion with facility managers. Criteria were that the area accommodated $<40$ residents, and permitted interaction between residents and the staff member to be trained in humour therapy.

All eligible residents within SMILE neighbourhoods were invited to participate. Residents were ineligible if they were $<50$ years of age, admitted to full-time care $<12$ weeks prior, exhibiting behaviour presenting a risk to 


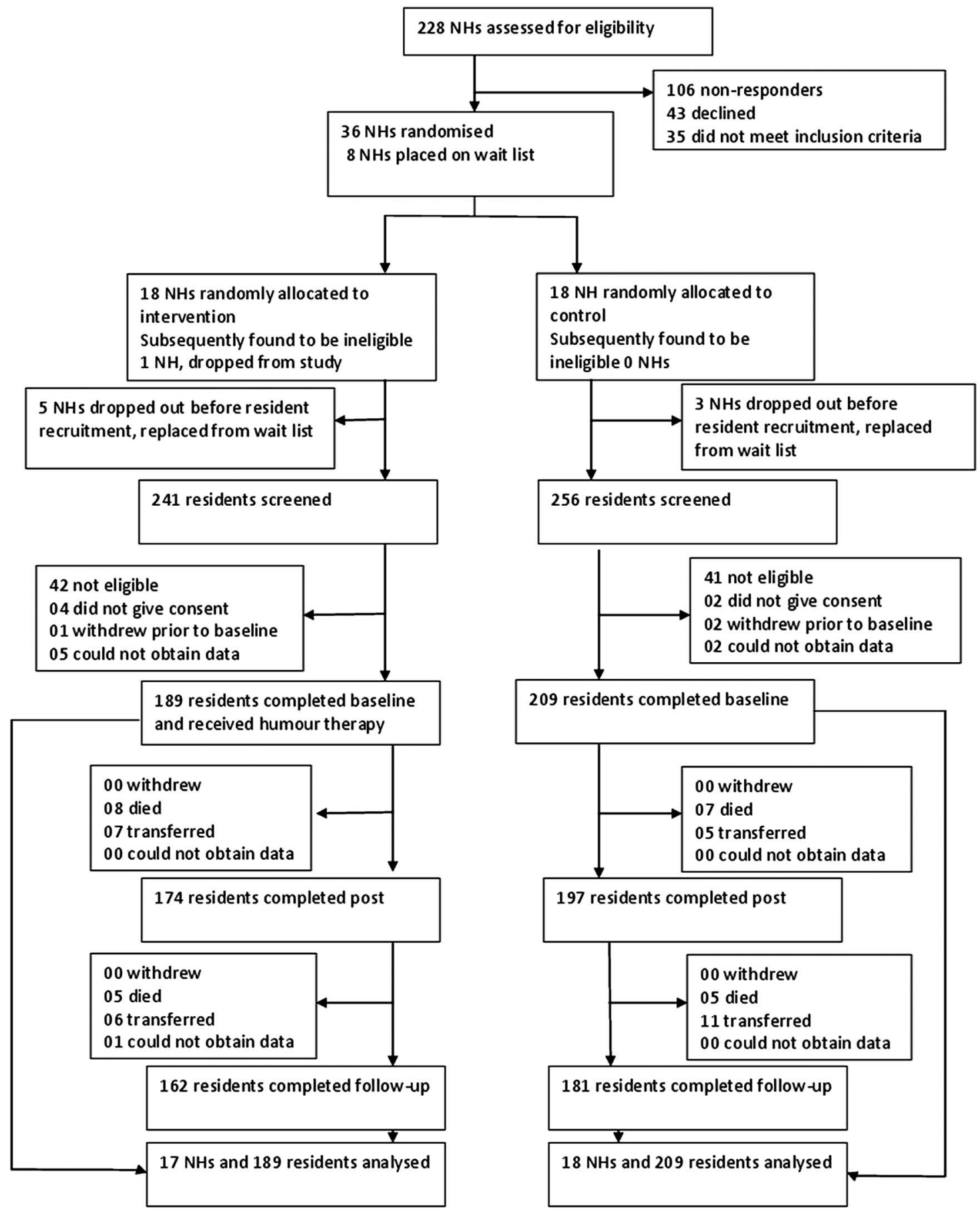

Figure 1 Pattern of nursing home $(\mathrm{NH})$ and resident recruitment and participation.

study personnel, foreshadowed to move out of the SMILE neighbourhood within 6 months, experiencing severe communication obstacles, acutely unwell, under public guardianship with no person responsible to consent on their behalf, or if they had florid psychiatric symptoms or a known fear of clowns or strangers (see figure 1).

\section{Intervention}

The humour therapy intervention comprised two components:
1. One-day LaughterBoss training for each home's nominated staff member. ${ }^{17}$ Training covered the evidence linking humour and health, and practical ways for including humour in daily care. LaughterBosses assisted during ElderClown visits and were encouraged to continue the humour intervention between and after ElderClown visits.

2. Between 9 and 12 humour therapy sessions by an ElderClown; ${ }^{18}$ a trained performer experienced in healthcare settings, who at each session visited with available and willing residents enrolled in the study. 
ElderClowns tailored their interactions to maximise resident engagement, laughter and enjoyment, adapting to the background, personality, mood and physical and cognitive abilities of the resident. ElderClowns prepared for their work with individual residents, and also improvised based on the residents' reactions and to make the conversation and interaction light hearted and playful. Interactions could be based around music-serenading the resident with their favourite song, or adapting a song to include their name, encouraging them to dance with each other or the LaughterBoss; could involve asking the resident's advice about a problem that the ElderClown has such as whether to buy a cat or a dog, or be based around jokes relating to a prop such as a slip-on rubber thumb with a light at the end. Interactions could occur in groups and individually depending on the resident's preferences.

For instance, a female resident with moderate dementia might have been engaged by an ElderClown asking her opinion about which hat would suit her best. Hats varied from a formal dress hat, to a sailor's hat to a silly costume hat with attached wig. The resident laughed at how the ElderClown looked in the hats and at her expressions and comments when wearing them, and made some joking comments about the hats. A male resident with severe dementia might have been engaged with a game of pretend tennis using plastic rackets and a ball on a wire. The LaughterBoss held one racket, the resident held the other and the ElderClown controlled the ball, making it easier or more difficult for the players to hit the ball, and also providing exaggerated commentary on the game. The resident tried to hit the ball, tracking it visually and smiled when he succeeded and was praised in the Elderclown's commentary. Information about residents was obtained from resident charts and presession briefings by the LaughterBoss. Postsession debriefing sessions between the ElderClown and LaughterBoss involved a discussion on what did and did not work, and formulation of ideas for the next visit. The trailer of a documentary showing ElderClown visits filmed during SMILE is available at http://thesmilewithin.com.au/.

\section{Randomisation and masking}

Enrolled homes were assigned a study number by the administrative assistant and deidentified characteristics were used for randomisation by the first author. SMILE neighbourhoods were stratified by size $(<25$ beds vs $\geq 25$ beds) and care level (high care vs low care). A random number generator in Excel was used to assign homes to intervention and control groups.

Only one investigator (LFL) and the administrative assistant were aware of treatment allocation before baseline assessment at each facility. Nursing homes and humour intervention staff were notified of treatment group by the administrative assistant after baseline. Reminders were given to nursing home staff prior to each occasion of contact to maintain blinding of data collectors. Nevertheless nursing home staff, residents or families revealed the blinding for 15 separate homes ( 5 control, 10 intervention) to one or two data collection staff, the remaining three data collection staff remained blinded throughout.

\section{Assessment}

Data were collected at three time points: baseline (week 0), post (week 13) and follow-up (week 26). Information was collected from the resident (if able and willing), a reliable staff informant, direct observation and from clinical files.

The primary outcome measure was The Cornell Scale for Depression in Dementia (CSDD) which is a clinicianrated depression scale. ${ }^{19}$ Secondary outcome measures were: the Cohen-Mansfield Agitation Inventory (CMAI) ${ }^{20}$ and the Neuropsychiatric Inventory Nursing Home ${ }^{21}$ to obtain informant ratings of the severity and frequency of 12 behavioural disturbances to assess informant-rated frequency of agitated behaviours; the eight-item withdrawal subscale of the Multidimensional Observation Scale for Elderly Subjects (MOSES) to measure informant rated social engagement, ${ }^{22}$ and the DEMQOL to provide proxy and self-rated measure of health-related quality of life. ${ }^{23}$

In addition, demographic information was collected, functional impairment was assessed using the Barthel Index, ${ }^{24}$ relative severity of dementia was rated using the Global Deterioration Scale, ${ }^{25}$ and the appropriateness of the physical environment for nursing home residents was rated at the facility level using the Environmental Audit Tool. ${ }^{26}$

After each ElderClown visit, the LaughterBoss and ElderClown independently completed global ratings of the level of success in engaging each resident on a 10-point scale (1=extremely unsuccessful to $10=$ extremely successful).

\section{Analyses}

A sample size of 36 homes with 9-10 residents in each was estimated to provide over $80 \%$ power to detect a medium effect size (Cohen's $d=0.5$ ) difference on continuous outcomes with significance level set at two-sided $0.05,{ }^{27}$ based on intraclass correlations on the outcome measures obtained from a previous multisite nursing home study. ${ }^{28}$

Analyses were conducted on an intention-to-treat basis by a statistician blind to group allocation using intention-to-treat analysis in SAS V.9.2 software. ${ }^{29}$ The $\alpha$ for significance was set at $\mathrm{p}=0.05$ for all analyses, such that we had $5 \%$ chance of incorrectly rejecting the null hypothesis for each test. Baseline differences in characteristics and outcome measures between groups were examined using t tests for normally distributed continuous data, $\chi^{2}$ tests for categorical data or Mann-Whitney $\mathrm{U}$ tests for non-normally distributed continuous data. Restricted maximum likelihood-based multilevel linear mixed models were employed to estimate the intervention effect, taking into account both within-resident correlation (repeated measures) and within-cluster (nursing home) correlation of the endpoints via random effect specification. ${ }^{30}$ Baseline response was adjusted using an approach recommended by Fitzmaurice et al..$^{31}$ All 
outcome measures were continuous, and data from all three time points were included as endpoints in the model. Intervention by time interaction was estimated to test for global group differences and for global change over time between groups. Potential confounding characteristics of homes and residents were included as clusterlevel or individual-level fixed or time-varying covariates and retained if evidence of confounding occurred (ie, if estimates of treatment effect differed substantially in the adjusted vs unadjusted models, or they explained significant variation in the outcomes). The Blom transformation was used to account for data skewness. ${ }^{32}$

The effect of engagement dose on outcomes was explored further within the intervention group. Dose was calculated as the total of engagement score for all visits, averaged across LaughterBoss and ElderClown ratings which were highly correlated $\left(r_{(1475)}=0.863\right.$, $\mathrm{p}<0.001)$. Statistical analysis was conducted in a similar manner to the primary analysis as outlined above.

\section{RESULTS}

Figure 1 shows trial recruitment and participant flow to achieve the final analysis sample of 209 usual care control group residents from 18 homes (7 low care, 11 high care) and 189 humour therapy group residents from 17 homes
(7 low care, 10 high care). Baseline characteristics of the intervention and control groups are shown in Table 1. There were no significant differences on demographic characteristics between the groups. Intervention group residents were taking slightly more regular psychotropic medications on average and were rated by staff as having higher levels of agitation on the CMAI.

A total of 191 humour therapy sessions were delivered (average of $11, \mathrm{SD}=1$ per facility), with individual residents receiving an average of $9(\mathrm{SD}=3)$ ElderClown visits.

Table 2 shows the raw mean scores by group and the three assessment occasions for the five resident outcome measures, the model adjusted mean difference in change between groups, and the primary analysis results. Depression and social engagement decreased and resident-rated dementia quality-of-life increased over time, but the group by time interactions on depression, nonagitation behavioural disturbance, social engagement or resident-rated or proxy-rated quality-of-life were nonsignificant $(p>0.05)$. The group-by-time interaction was significant for agitation measured using the CMAI, before and after adjustment for covariates $(\mathrm{p}<0.05)$. The adjusted mean differences of change based on Blom-transformed scores indicates that the humour therapy group decreased on the CMAI by 0.17 (95\% CI 0.004 to $0.34 ; p=0.045$ ) points more than controls between baseline and follow-up,

Table 1 Baseline characteristics of residents and SMILE neighbourhoods by group

\begin{tabular}{|c|c|c|c|}
\hline & $\begin{array}{l}\text { Usual care controls }(n=209 \text {, } \\
18 \text { facilities) }\end{array}$ & $\begin{array}{l}\text { Humour therapy }(n=189 \text {, } \\
17 \text { facilities) }\end{array}$ & Test statistic \\
\hline \multicolumn{4}{|l|}{ SMILE neighbourhoods } \\
\hline Number of residents & $22.1 \pm 8.6$ & $19.1 \pm 7.7$ & $t_{(33)}=1.08, p=0.29$ \\
\hline $\begin{array}{l}\text { Number of residents who } \\
\text { participated }\end{array}$ & $10.8 \pm 3.3$ & $11.3 \pm 2.3$ & $t_{(33)}=0.67, p=0.51$ \\
\hline \multicolumn{4}{|l|}{ Residents } \\
\hline Age in years & $84.5 \pm 8.7$ & $84.5 \pm 7.5$ & $t_{(396)}=-0.09, p=0.93$ \\
\hline Number of females & $161(77.0 \%)$ & $146(77.2 \%)$ & $X_{(1)}^{2}=0.00, p=0.96$ \\
\hline $\begin{array}{l}\text { Number with dementia diagnoses } \\
\text { in chart }\end{array}$ & $165(78.9 \%)$ & $145(76.7 \%)$ & $X_{(1)}^{2}=0.29, p=0.59$ \\
\hline Years lived in care & $2.7 \pm 2.8$ & $2.8 \pm 3.1$ & $U=19153.0, p=0.66$ \\
\hline Global Deterioration Scale & $5.0 \pm 1.2$ & $5.0 \pm 1.2$ & $U=19573.0, p=0.87$ \\
\hline $\begin{array}{l}\text { Number with English as a first } \\
\text { language }\end{array}$ & $204(97.6 \%)$ & $186(98.4 \%)$ & $X_{(1)}^{2}=0.32, p=0.57$ \\
\hline $\begin{array}{l}\text { Number of regular psychotropic } \\
\text { medications }\end{array}$ & $1.0 \pm 1.0$ & $1.2 \pm 1.0$ & $U=17484.0, p=0.045$ \\
\hline Barthel & $41.5 \pm 24.5$ & $42.3 \pm 25.2$ & $U=19397.5, p=0.76$ \\
\hline $\begin{array}{l}\text { Cornell Scale for Depression in } \\
\text { Dementia }\end{array}$ & $7.8 \pm 5.6$ & $8.5 \pm 6.1$ & $U=18565.5, p=0.34$ \\
\hline $\begin{array}{l}\text { Cohen-Mansfield Agitation } \\
\text { Inventory }\end{array}$ & $38.9 \pm 11.0$ & $45.3 \pm 20.0$ & $U=16897.0, p=0.012$ \\
\hline Neuropsychiatric Inventory & $18.7 \pm 16.9$ & $22.3 \pm 21.7$ & $U=18771.5, p=0.39$ \\
\hline DEMQOL-resident & $89.9 \pm 13.8$ & $89.4 \pm 15.5$ & $U=8818.5, p=0.89$ \\
\hline DEMQOL-proxy & $106.0 \pm 13.4$ & $103.5 \pm 11.1$ & $U=17266.0, p=0.075$ \\
\hline $\begin{array}{l}\text { MOSES social engagement } \\
\text { subscale }\end{array}$ & $18.1 \pm 6.2$ & $17.4 \pm 6.0$ & $U=18401.5, p=0.24$ \\
\hline
\end{tabular}

Figures are means and SDs of scores unless otherwise stated.

SMILE, Sydney Multisite Intervention of LaughterBosses and ElderClowns; MOSES, Multidimensional Observation Scale for Elderly Subjects. 
Table 2 Effect of humour therapy on outcome measures over time at resident level

\begin{tabular}{|c|c|c|c|c|c|c|c|c|}
\hline & $\begin{array}{l}\text { Baseline } \\
(n=398)^{\star}\end{array}$ & Post $(n=371)^{*}$ & $\begin{array}{l}\text { Follow-up } \\
(n=343)^{\star}\end{array}$ & $\begin{array}{l}\text { Adjusted mean } \\
\text { difference } \\
\text { baseline-post ( } 95 \% \\
\mathrm{Cl})\end{array}$ & p Value & $\begin{array}{l}\text { Adjusted mean difference } \\
\text { baseline-follow-up ( } 95 \% \\
\text { Cl) }\end{array}$ & p Value & $\begin{array}{l}\text { Intracluster } \\
\text { correlation } \\
\text { coefficient }\end{array}$ \\
\hline Depression (CSDD) & \multicolumn{8}{|c|}{$p_{G}=0.68, p_{T}<0.01, p_{G T}=0.88 ; p_{G c}=0.50, p_{T c}<0.01, p_{G T c}=0.89$} \\
\hline Control & $7.8 \pm 5.6$ & $6.5 \pm 4.5$ & $6.3 \pm 5.4$ & $0.006(-0.19$ to 0.20$)$ & 0.95 & $0.046(-0.18$ to 0.27$)$ & 0.69 & 0.12 \\
\hline Intervention & $8.5 \pm 6.1$ & $6.9 \pm 5.2$ & $6.4 \pm 4.8$ & & & & & \\
\hline Agitation (CMAI) & \multicolumn{8}{|c|}{$p_{G}=0.33, p_{T}=0.22, p_{G T}=0.01 ; p_{G c}=0.20, p_{T c}=0.02, p_{G T c}=0.01$} \\
\hline Control & $38.9 \pm 11.0$ & $37.9 \pm 10.0$ & $39.0 \pm 11.7$ & $-0.04(-0.18$ to 0.11$)$ & 0.61 & $0.17(0.004$ to 0.34$)$ & 0.045 & 0.15 \\
\hline Intervention & $45.3 \pm 20.0$ & $43.4 \pm 19.1$ & $42.0 \pm 18.3$ & & & & & \\
\hline $\begin{array}{l}\text { Behavioural } \\
\text { disturbance (NPI) }\end{array}$ & \multicolumn{8}{|c|}{$p_{G}=0.69, p_{T}=0.63, p_{G T}=0.07 ; p_{G c}=0.47, p_{T c}=0.49, p_{G T c}=0.09$} \\
\hline Control & $18.7 \pm 16.9$ & $19.3 \pm 15.7$ & $18.1 \pm 16.8$ & 0.05 (-0.11 to 0.22$)$ & 0.52 & $-0.15(-0.34$ to 0.04$)$ & 0.13 & 0.18 \\
\hline Intervention & $22.3 \pm 21.7$ & $20.0 \pm 20.3$ & $23.2 \pm 22.0$ & & & & & \\
\hline $\begin{array}{l}\text { Social engagement } \\
\text { (MOSES) }\end{array}$ & \multicolumn{8}{|c|}{$\mathrm{p}_{\mathrm{G}}=0.44, \mathrm{p}_{\mathrm{T}}<0.01, \mathrm{p}_{\mathrm{GT}}=0.62 ; \mathrm{p}_{\mathrm{Gc}}=0.41, \mathrm{p}_{\mathrm{Tc}}<0.01, \mathrm{p}_{\mathrm{GTc}}=0.45$} \\
\hline Control & $18.2 \pm 6.0$ & $18.2 \pm 6.0$ & $18.7 \pm 6.3$ & $-0.046(-0.21$ to 0.12$)$ & 0.58 & $0.049(-0.13$ to 0.22$)$ & 0.59 & 0.12 \\
\hline Intervention & $17.3 \pm 6.0$ & $17.6 \pm 6.4$ & $18.1 \pm 6.1$ & & & & & \\
\hline $\begin{array}{l}\text { Resident-rated quality } \\
\text { of life (DEMQOL-res) }\end{array}$ & \multicolumn{8}{|c|}{$\mathrm{p}_{\mathrm{G}}=0.72, \mathrm{p}_{\mathrm{T}}<0.01, \mathrm{p}_{\mathrm{GT}}=0.29 ; \mathrm{p}_{\mathrm{Gc}}=0.51 \mathrm{p}_{\mathrm{Tc}}=<0.01, \mathrm{p}_{\mathrm{GTC}}=0.41$} \\
\hline Control & $89.9 \pm 13.8$ & $92.9 \pm 12.7$ & $92.5 \pm 15.4$ & $-0.10(-0.31$ to 0.11$)$ & 0.34 & $0.05(-0.18$ to 0.28$)$ & 0.67 & 0.06 \\
\hline Intervention & $89.4 \pm 5.5$ & $93.7 \pm 13.1$ & $92.0 \pm 14.0$ & & & & & \\
\hline $\begin{array}{l}\text { Staff-rated } \\
\text { quality-of-life } \\
\text { (DEMQOL-proxy) }\end{array}$ & \multicolumn{8}{|c|}{$p_{G}=0.13, p_{T}=<0.01, p_{G T}=0.44 ; p_{G c}=0.11, p_{T c}=<0.01, p_{G T c}=0.40$} \\
\hline Control & $106.0 \pm 13.4$ & $104.5 \pm 16.3$ & $103.2 \pm 11.8$ & $0.07(-0.16$ to 0.31$)$ & 0.53 & $-0.07(-0.28$ to 0.13$)$ & 0.48 & 0.40 \\
\hline Intervention & $103.5 \pm 11.1$ & $100.6 \pm 14.9$ & $101.4 \pm 11.7$ & & & & & \\
\hline
\end{tabular}

Adjusted mean scores are based on the standardised (Blom-transformed) scores. Positive scores indicate improvement.

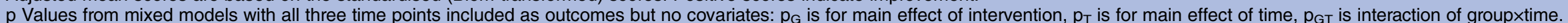

$p$ Values for mixed models including significant covariates: $p_{G c}$ is for main effect of intervention, $p_{T c}$ is for main effect of time, $p_{G T c}$ is interaction of groupxtime.

$p$ Values for mixed models including significant covarat: $P_{G c}$ is for main effect of intervention, P

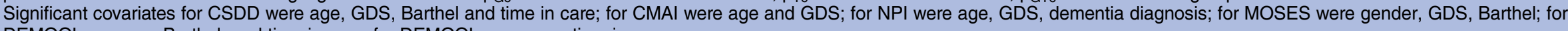
DEMQOL-res were Barthel, and time in care; for DEMQOL-proxy was time in care.

${ }^{*}$ Data are raw non-transformed scores.

CMAI, Cohen-Mansfield Agitation Inventory; CSDD, Cornell Scale for Depression in Dementia; GDS, Global Deterioration Scale; NPI, Neuropsychiatric Inventory 
the difference in raw scores was 2.52 (95\% CI 0.20 to 5.32 , $\mathrm{p}=0.07)$. The difference in change from post to follow-up on the CMAI was statistically significant with the adjusted mean difference being 0.21 (95\% CI 0.07 to 0.35 ; $\mathrm{p}=0.003)$ the difference in raw scores was 2.95 (95\% CI 0.89 to $5.02, \mathrm{p}=0.005)$. There were significant engagement dose-by-time interactions for depression $\left(\mathrm{F}_{(2,496)}=6.72\right.$, $\mathrm{p}=0.00)$, behavioural disturbance $\left(\mathrm{F}_{(2,497)}=3.49, \mathrm{p}=0.03\right)$ and resident-rated quality-of-life $\left(\mathrm{F}_{(2,337)}=3.39, \mathrm{p}=0.03\right)$, but not for the other outcome measures. Residents who experienced higher doses of engagement showed greater improvement on depression, behavioural disturbance and resident-rated quality-of-life.

No adverse events were reported after ElderClown sessions or generally in relation to humour therapy with LaughterBosses.

\section{DISCUSSION}

While there was no significant benefit on the primary outcome measure, depression, agitation levels decreased significantly over time with humour therapy compared with usual care with the mean adjusted change difference between baseline and follow-up being 2.52 points - this would be equivalent to two agitated behaviours decreasing in frequency from daily to once a week. Difference between treatment and control groups on change scores on the CMAI pooled across three randomised controlled trials of risperidone were 3 . (95\% CI 1.78 to 4.22$).{ }^{33}$ In decreasing agitation, humour therapy had a similar effect to risperidone, the most commonly used antipsychotic in Australia for the treatment of behavioural disturbance in dementia. ${ }^{34}$ Humour therapy showed none of the side effects of risperidone. When adjustments were made for the 'dosage' of humour therapy engagement, humour therapy demonstrated benefits on depression, behavioural disturbance and selfreported dementia quality-of-life effects not reported with medication.

The strengths of SMILE include: a large sample, clustered design and relatively high follow-up rates. We were able to implement our intervention in real-world nursing homes, despite initial reservations from some managers and staff. The sustained benefits in agitation at follow-up underscore the importance of recruiting staff members into the programme. Limitations are noted. First, data collection staff became 'unblinded' over time for 15 of the 35 homes despite constant reminders to nursing home staff ahead of data collection periods of the importance of maintaining confidentiality of intervention allocation. Second, participating homes might not have been representative of Australian nursing homes. Compared with national data, residents in our sample were similar in average age and dependency level, but were $6 \%$ more likely to be female, required less help with activities of daily living and had higher levels of behavioural disturbances. Third, there were variations between residents in the number of ElderClown sessions they received, and variations between homes in the amount of humour initiated by LaughterBosses outside ElderClown sessions. LaughterBosses were not tested for competency in delivering humour. Fourth, the two groups were unbalanced at baseline on several outcome measures, these differences were adjusted for in our statistical modelling. Fifth, adjustment for multiple comparisons was not made to the $\alpha$ for significance, as outcome measures were correlated. Sixth, the intracluster correlations for this sample were much higher than reported in the study on which our power calculations were based, which resulted in lower power than planned.

Several explanations are possible for the lack of effect on outcome measures other than CMAI agitation. Depression, other forms of behavioural disturbances and self-rated quality-of-life all improved more in residents who experienced higher doses of engagement as a result of humour therapy, suggesting that humour therapy does change these outcomes, even though there was not a statistical advantage of intervention over control groups. There was a floor effect: only $29 \%$ of our sample was assessed as having probable or possible depression on the CSDD, and $28 \%$ of our sample was rated as not having any agitation symptoms on the CMAI, thereby limiting the potential for improvement. The DEMQOL was developed for persons with mild to severe dementia; however, $33 \%$ of residents were unable to complete the self-report version. While we interviewed staff members who knew the resident well, it was difficult for staff to be aware of the quality-of-life related concerns of many residents, particularly those with poor verbal skills. Our data and others showed that DEMQOL proxy scores correlate only mildly or moderately with DEMQOL self-report. The measures used might not have been sensitive to anecdotally reported positive effects such as increased positive mood, and increased initiation of and participation in social activities.

We offered a novel model of humour therapy delivery combining staff training (LaughterBosses) and professional humour therapists (ElderClowns). This was designed to minimise costs and deliver sustainable practice change within nursing homes. We believe that the active ingredients of the programme are engagement and play. This is supported by our engagement dose analyses and consistent with a needs-driven behaviour explanatory model of behaviours. ${ }^{35}$ Increasing social contact and opportunities for play could have fulfilled a need for stimulation which is expressed through agitation. Other tailored models of engaging and stimulating residents might also be successful. ${ }^{36}$ Challenges in delivering the programme predominantly related to false expectations that, rather than attempting to elicit individual responses from residents enrolled in the study, the ElderClown would perform for any audience. Some suggest that the label 'ElderClown' might not be appropriate in describing the work of the professional performers.

SMILE demonstrated that there are benefits to increasing positive interactions for residents. If our 
results are replicated, consideration should be given to systematically introducing humour therapy as a psychosocial intervention to reduce the level of agitation in nursing home residents. More research is needed into the efficacy of different models of delivering humour therapy.

\section{Author affiliations}

${ }^{1}$ Dementia Collaborative Research Centre, Centre for Healthy Brain Ageing, School of Psychiatry, University of New South Wales, Sydney, Australia

${ }^{2}$ Humour Foundation, Chatswood, New South Wales, Australia

${ }^{3}$ Arts Health Institute, Newcastle, New South Wales, Australia

${ }^{4}$ NSW \& ACT Dementia Training Study Centre, University of Wollongong,

Wollongong, New South Wales, Australia

${ }^{5}$ Health and Ageing Research Unit, University of Technology, Sydney, New South Wales, Australia

Acknowledgements The authors would like to thank the SMILE research and humour therapy teams, and the participating nursing homes, residents, families and staff.

Contributors All authors had full access to all of the data (including statistical reports and tables) in the study and take responsibility for the integrity of the data and the accuracy of the data analysis. HB, PS, L-FL, LC and RF participated in study concept and design. BG, A-NC, PB and PS participated in acquisition of data. L-FL, ZL and HB participated in statistical analysis and interpretation of data. L-FL, HB, BG, PS, PB, RF, A-NC, ZL and LC participated in critical revision of the manuscript for important intellectual content. HB, L-FL, LC, RF and PS obtained funding. HB, L-FL and BG participated in study supervision.

Funding The National Health and Medical Research Council had no role in study design, collection, analysis or interpretation of data, writing or deciding to submit this paper for publication.

Competing interests All authors have completed the Unified Competing Interest form at http://www.icmje.org/coi_disclosure.pdf (available on request from the corresponding author) and declare: funding for the submitted work from the National Health and Medical Research Council grants 568787 and 455377; PS and JPB both received payments for delivery of the humour therapy intervention from the not-for-profit organisation The Humour Foundation; PS is the Medical Director and board member of The Humour Foundation. JPB and LFL are board members for the not-for-profit Arts Health Institute which also provides humour therapy services; no other relationships or activities that could appear to have influenced the submitted work.

Ethics approval University of New South Wales Human Research Ethics Committee-approval no. 08345;

Provenance and peer review Not commissioned; externally peer reviewed.

Data sharing statement There are no additional data available.

\section{REFERENCES}

1. Martin R. The psychology of humour: an integrative approach. Burlington, MA: Elsevier Inc, 2007.

2. Friedler S, Glasser S, Azani L, et al. The effect of medical clowning on pregnancy rates after in vitro fertilization and embryo transfer. Fertil Steril 2011;95:2127-30.

3. Costa Fernandes S, Arriaga P. The effects of clown intervention on worries and emotional responses in children undergoing surgery. $J$ Health Psychol 2010;15:405-15.

4. Bertini M, Isola $\mathrm{E}$, Paolone $\mathrm{G}$, et al. Clowns benefit children hospitalized for respiratory pathologies. Evid Complement Alternat Med 2011. doi:10.1093/ecam/neq064.

5. Shahidi M, Mojtahed A, Modabbernia A, et al. Laughter yoga versus group exercise program in elderly depressed women: a randomized controlled trial. Int J Geriatr Psychiatry 2011;26:322-27.

6. Ko HJ, Youn $\mathrm{CH}$. Effects of laughter therapy on depression, cognition and sleep among the community-dwelling elderly. Geriatr Gerontol Int 2011;11:267-74.

7. Moos I. Humour, irony and sarcasm in severe Alzheimer's dementia -a corrective to retrogenesis? Ageing Soc 2011;31:328-46.
8. Henry JD, Rendell PG, Scicluna A, et al. Emotion experience, expression, and regulation in Alzheimer's disease. Psychol Aging 2009;24:252-7.

9. Isola A, Astedt-Kurki P. Humour as experienced by patients and nurses in aged nursing in Finland. Int $J$ Nurs Pract 1997:3:29-33.

10. Thomson R. Evaluation of the use of a clown therapy group with dementia sufferers. NHS Borders Pychological Serv 2005:3-4.

11. Houston DM, McKee KJ, Carroll L, et al. Using humour to promote psychological wellbeing in residential homes for older people. Aging Mental Health 1998;2:328-32.

12. Boyd R, McGuire $F$. The efficacy of humor in improving psychological well-being of residents of long-term care facilities. $J$ Leisurability 1996;23:1-15.

13. Ronnberg L. Quality of life in nursing-home residents: an intervention study of the effect of mental stimulation through an audiovisual programme. Age Ageing 1998;27:393-7.

14. Tse MY, Lo APK, Cheng TLY, et al. Humor therapy: relieving chronic pain and enhancing happiness for older adults (Article ID 343574). $J$ Ageing Res 2010. doi:10.4061/2010/343574

15. Walter M, Hänni B, Haug M, et al. Humour therapy in patients with late-life depression or Alzheimer's disease: a pilot study. Int J Geriatr Psychiatry 2007;22:77-83.

16. Goodenough B, Low L-F, Casey A-N, et al. Study protocol for a randomized controlled trial of humor therapy in residential care: the Sydney Multisite Intervention of LaughterBosses and ElderClowns (SMILE). Int Psychogeriatr 2012;24:2037-44.

17. Spitzer P. The LaughterBoss. In: Adams T, Lee H.eds. Creative approaches in dementia care. New York: Palgrave MacMillan, 2011:32-53.

18. Warren B, Spitzer P. The art of medicine: laughing to longevity-the work of elder clowns. Lancet 2011;378:562-3.

19. Alexopolous G, Abrams R, Young R, et al. Scale for depression in dementia. Biol Psychiatry 1988;23:271-84.

20. Cohen-Mansfield J. A description of agitation in a nursing home. J Gerontol 1989;44:M77-84.

21. Cummings JL, Mega M, Gray K, et al. The neuropsychiatric inventory: comprehensive assessment of psychopathology in dementia. Neurology 1994:44:2308-14.

22. Helmes E, Csapo K, Short J-A. Standardization and validation of the Multidimensional Observation Scale for Elderly Subjects (MOSES). $J$ Gerontol 1987;42:395-405.

23. Banerjee S, Smith SC, Lamping DL, et al. Quality of life in dementia: more than just cognition. An analysis of associations with quality of life in dementia. J Neurol Neurosurg Psychiatry 2006;77:146-8.

24. Mahoney FI, Barthel DW. Functional evaluation: the Barthel Index. Md State Med J 1965;14:61-5.

25. Reisberg B, Ferris SH, de Leon MJ, et al. The Global Deterioration Scale for assessment of primary degenerative dementia. $A m$ J Psychiatry 1982;139:1136-9.

26. Fleming R. An environmental audit tool suitable for use in homelike facilities for people with dementia. Australas J Ageing 2011;30:108-12.

27. Hayes RJ, Bennett S. Simple sample size calculation for cluster-randomized trials. Int J Epidemiol 1999;28:319-26.

28. Chenoweth L, King MT, Jeon YH, et al. Caring for Aged Dementia Care Resident Study (CADRES) of person-centred care, dementia-care mapping, and usual care in dementia: a cluster-randomised trial. Lancet Neurol 2009;8:317-25.

29. SAS Institute Inc. Base SAS ${ }^{\circ}$ V9.2 proceedures guide. Cary, NC: SAS Institute Inc, 2011.

30. Murray DM. Design and analysis of group-randomised trials. Oxford, UK: Oxford University Press, 1998.

31. Fitzmaurice G, Laird N, Ware J. Applied longitudinal analysis. New Jersey: John Wiley \& Sons, 2004.

32. Blom G. Statistical estimates and transformed beta variables. New York: John Wiley \& Sons, 1958.

33. Schneider LS, Dagerman K, Insel PS. Efficacy and adverse effects of atypical antipsychotics for dementia: meta-analysis of randomized, placebo-controlled trials. Am J Geriatr Psychiatry 2006;14:191-210.

34. Snowdon J, Galanos D, Vaswani D. Patterns of psychotropic medication use in nursing homes: surveys in Sydney, allowing comparisons over time and between countries. Int Psychogeriatr 2011;23:1520-5.

35. Algase DL, Beck C, Kolanowski A, et al. Need-driven dementia-compromised behavior: an alternative view of disruptive behavior. Am J Alzheimer's Dis Other Demen 1996;11:10-19.

36. Gitlin LN, Winter L, Burke $\mathrm{J}$, et al. Tailored activities to manage neuropsychiatric behaviors in persons with dementia and reduce caregiver burden: a randomized pilot study. Am J Geriatr Psychiatry 2008;16:229-39. 